University of Nebraska - Lincoln

DigitalCommons@University of Nebraska - Lincoln

West Central Research and Extension Center, North Platte

2010

\title{
Effects of maternal nutrition on conceptus growth and offspring performance: Implications for beef cattle production
}

Richard N. Funston

University of Nebraska - Lincoln, rfunston2@unl.edu

David M. Larson

University of Nebraska-Lincoln

K. A. Vonnahme

North Dakota State University - Main Campus

Follow this and additional works at: https://digitalcommons.unl.edu/westcentresext

Part of the Agriculture Commons

Funston, Richard N.; Larson, David M.; and Vonnahme, K. A., "Effects of maternal nutrition on conceptus growth and offspring performance: Implications for beef cattle production" (2010). West Central Research and Extension Center, North Platte. 22.

https://digitalcommons.unl.edu/westcentresext/22

This Article is brought to you for free and open access by the Agricultural Research Division of IANR at DigitalCommons@University of Nebraska - Lincoln. It has been accepted for inclusion in West Central Research and Extension Center, North Platte by an authorized administrator of DigitalCommons@University of Nebraska - Lincoln. 


\title{
Effects of maternal nutrition on conceptus growth and offspring performance: Implications for beef cattle production ${ }^{1}$
}

\author{
R. N. Funston, ${ }^{* 2}$ D. M. Larson, ${ }^{*}$ and K. A. Vonnahme $\dagger$ \\ *West Central Research and Extension Center, University of Nebraska, North Platte 69101; \\ and $\dagger$ Center for Nutrition and Pregnancy, Department of Animal Sciences, \\ North Dakota State University, Fargo 58108
}

\begin{abstract}
Developmental programming is the concept that a maternal stimulus or insult at a critical period in fetal development has long-term effects on the offspring. Historically, considerable effort has been made to understand how nutrition influences health and productivity during the postnatal period. Whereas maternal nutrition during pregnancy plays an essential role in proper fetal and placental development, less is known about how maternal nutrition affects the health and productivity of the offspring. Conceptus growth is sensitive to direct and indirect effects of maternal dietary intake. Even from the earliest stages of embryonic life, when nutrient requirements for conceptus growth are negligible, alterations in tissue composition can occur, influencing future growth of the compromised or-
\end{abstract}

gan system. Not only is neonatal health compromised, but subsequent health may also be programmed because offspring from undernourished dams have exhibited poor growth and productivity and have developed significant diseases later in life. Although the literature is now evolving, with increasing evidence of how maternal nutrient restriction impairs several prenatal physiological variables, few studies have evaluated postnatal growth and development in livestock species, and fewer have evaluated it in beef cattle. In addition, very few studies have evaluated restriction of specific components of the diet during pregnancy (such as protein) on offspring growth and performance. This review focuses on how maternal nutrition affects conceptus growth and postnatal responses in beef cattle.

Key words: beef cattle, developmental programming, nutrition, pregnancy

(C)2010 American Society of Animal Science. All rights reserved. J. Anim. Sci. 2010. 88(E. Suppl.):E205-E215
doi:10.2527/jas.2009-2351

\section{INTRODUCTION}

Maternal nutritional status is one of the extrinsic factors programming nutrient partitioning and ultimately growth, development, and function of the major fetal organ systems (Wallace, 1948; Wallace et al., 1999; Godfrey and Barker, 2000). Indeed, the prenatal growth trajectory is sensitive to the direct and indirect effects of maternal dietary intake from the earliest stages of embryonic life, when the nutrient requirements for conceptus growth are negligible (Robinson et al., 1995). This is especially relevant because preterm delivery

\footnotetext{
${ }^{1}$ Based on a presentation at the Triennial Reproduction Symposium titled "Challenges and opportunities facing livestock reproduction in the 21st century," at the Joint Annual Meeting, July 12 to 16, 2009, Montreal, Canada. The symposium was sponsored, in part, by the ASAS Foundation, EAAP, Lauderdale Appreciation Club, Intervet/Schering-Plough Animal Health, and Pfizer Animal Health, with publication sponsored by the Journal of Animal Science and the American Society of Animal Science.

${ }^{2}$ Corresponding author: rfunston2@unl.edu

Received July 30, 2009.

Accepted September 30, 2009.
}

and fetal growth restriction are associated with greater risk of neonatal mortality and morbidity in livestock and humans. In all livestock species, including cattle, offspring born at an above-average BW have an increased chance of survival compared with those born at a below-average BW. Growth-restricted human infants not only are at risk of immediate postnatal complications, but also may be programmed to exhibit poor growth performance and to develop significant diseases later in life (Barker et al., 1993; Godfrey and Barker, 2000), and there is increasing evidence that production characteristics in livestock may also be affected by maternal diet (Wu et al., 2006). Some of the complications reported in livestock include increased neonatal mortalities, intestinal and respiratory dysfunction, slow postnatal growth, increased fat deposition, differing muscle fiber diameters, and reduced meat quality (Wu et al., 2006).

The objective of this review is to highlight the nutritional paradigms that have been studied in the beef cow and how nutrition during pregnancy affects pre- and postnatal growth and development of the calf. Although this review primarily focuses on maternal nutrition in 
beef cattle, examples from other gestational stressors and other species are used for clarification.

\section{EARLY PREGNANCY AND PLACENTAL DEVELOPMENT}

Inadequate nutrition during early gestation may appear to be unimportant because of the limited nutrient requirements of the fetus for growth and development during the first one-half of gestation. This is accentuated by the fact $75 \%$ of the growth of the ruminant fetus occurs during the last 2 mo of gestation (Robinson et al., 1977). During the early phase of fetal development, however, maximal placental growth, differentiation, and vascularization occur, as well as fetal organogenesis, all of which are critical events for normal conceptus development.

The placenta plays a major role in the regulation of fetal growth. In ruminants, the fetal placenta attaches to discrete sites on the uterine wall called caruncles. These caruncles are aglandular sites that appear as knobs along the uterine luminal surface of nonpregnant animals, and are arranged in 2 dorsal and 2 ventral rows throughout the length of the uterine horns. The placental membranes attach at these sites via chorionic villi in areas termed cotyledons. The caruncular-cotyledonary unit is called a placentome and is the primary functional area of physiological exchanges between mother and fetus. Placental nutrient transport efficiency is directly related to uteroplacental blood flow (Reynolds and Redmer, 1995). All the respiratory gases, nutrients, and wastes that are exchanged between the maternal and fetal systems are transported via the uteroplacenta (Reynolds and Redmer, 1995, 2001). Thus, it is not surprising that fetal growth restriction in several experimental paradigms is closely correlated with reduced uteroplacental growth and development (Reynolds and Redmer, 1995, 2001). Establishment of functional fetal and uteroplacental circulation is one of the earliest events during embryonic and placental development (Patten, 1964; Ramsey, 1982). It has been shown that the large increase in transplacental exchange, which supports the exponential increase in fetal growth during the last one-half of gestation, depends primarily on the dramatic growth of the uteroplacental vascular beds during the first one-half of pregnancy (Meschia, 1983; Reynolds and Redmer, 1995). Therefore, an understanding of factors that affect uteroplacental blood flow will directly affect placental efficiency and thus fetal growth. However, despite intensive research in the area of placental-fetal interactions, the regulators of placental growth and vascularization, as well as those of uteroplacental blood flow, are still largely unknown, particularly in cattle.

Surprisingly, few data are available outlining the vascular development of the bovine placenta. Recently, Vonnahme et al. (2007) have demonstrated that global nutrient restriction during early gestation (i.e., d 30 to
125 ), followed by realimentation during d 125 to 250 affects placental angiogenesis (i.e., capillary vascularity), as well as angiogenic factor mRNA abundance in the beef cow. It was demonstrated that mRNA abundance of genes that are known to increase vascular permeability [i.e., placental growth factor and vascular endothelial growth factor (VEGF) receptor 1; Peters et al., 1993; Odorisio et al., 2002] were increased in both the caruncular and cotyledonary tissues at the end of the nutrient restriction period. However, capillary vascularity measurements were not altered in either the cotyledon or the caruncular tissues at the end of the nutrient restriction on d 125. Interestingly, after realimentation from d 125 to 250 of gestation, there were dramatic differences in capillary vascularity measurements. In the cotyledon, or fetal portion of the placentome, 3 of the 4 measurements for capillary vascularity [i.e., capillary area density (CAD), a flow-related measure; capillary number density (CND), an angiogenesis-related measure; and capillary surface density (CSD), an nutrientexchange measure] were decreased in placentomes from cows previously nutrient restricted (NR) compared with control cows, demonstrating that the capillary area, numbers, and surface densities had been hindered upon realimentation. However, in the caruncular tissue, or maternal placentome, the CSD in realimented NR cows were increased compared with cows that had adequate nutrition throughout gestation (Vonnahme et al., 2007). The process of realimentation caused an interesting differential change in vascular structure of the cotyledonary and caruncular tissue in the placentome.

Reports of changes in placental vascularity in response to realimentation of NR ewes and cows are very limited. McMullen et al. (2005) demonstrated that a short duration (i.e., $7 \mathrm{~d}$ ) of fasting during mid-pregnancy in the ewe resulted in a decrease in mRNA abundance of the angiogenic factor, VEGF, and placental weights on d 90. Although differences in VEGF mRNA were not evaluated at term, placental weights were similar at lambing in NR and control ewes. In cows, there was a decrease in total placentome weight on d 125 in NR vs. control cows that remained suppressed even after realimentation on d 250 (Vonnahme et al., 2007; Zhu et al., 2007). Looking more closely at placentome weight in the cow, both the cotyledonary and caruncular portions were decreased in NR vs. control cows at the end of the nutrient restriction on $\mathrm{d} 125$; however, only the weight of the cotyledonary tissue remained suppressed at d 250. In contrast, in several studies in which ewes experienced nutrient restriction from early to mid-pregnancy and were then realimented, significant compensatory growth of the entire placentome was found to occur (Foote et al., 1958; Robinson et al., 1995; Heasman et al., 1998; McMullen et al., 2005).

The differences in the effects of nutrient restriction and realimentation in the cow (Vonnahme et al., 2007) and the sheep models described above may result from inherent species differences in placental development between sheep and cattle, or may result from the type 
of diet these cows received upon realimentation. In ewes, the growth of the cotyledonary mass is exponential during the first 10 to $11 \mathrm{wk}$ of pregnancy, thereafter slowing markedly until term (Stegeman, 1974). In the cow, the cotyledonary growth progressively increases throughout gestation (Reynolds et al., 1990; Vonnahme et al., 2007). Using the same vascularity determination techniques as used in tissue from cows, Vonnahme et al. (2007) showed in sheep that caruncular tissue, CAD, CND, CSD, and capillary size increased by 214, 37, 140 , and $45 \%$ from d 50 to 140 in normal pregnancy (gestation length of sheep, approximately $147 \mathrm{~d}$; Reynolds et al., 2005; Borowicz et al., 2007; Figure 1). In ovine cotyledons, CAD, CND, CSD increased by 437 , 1,093 , and $576 \%$, and capillary size decreased by $24.8 \%$ from d 50 to 140 in normal pregnancy.
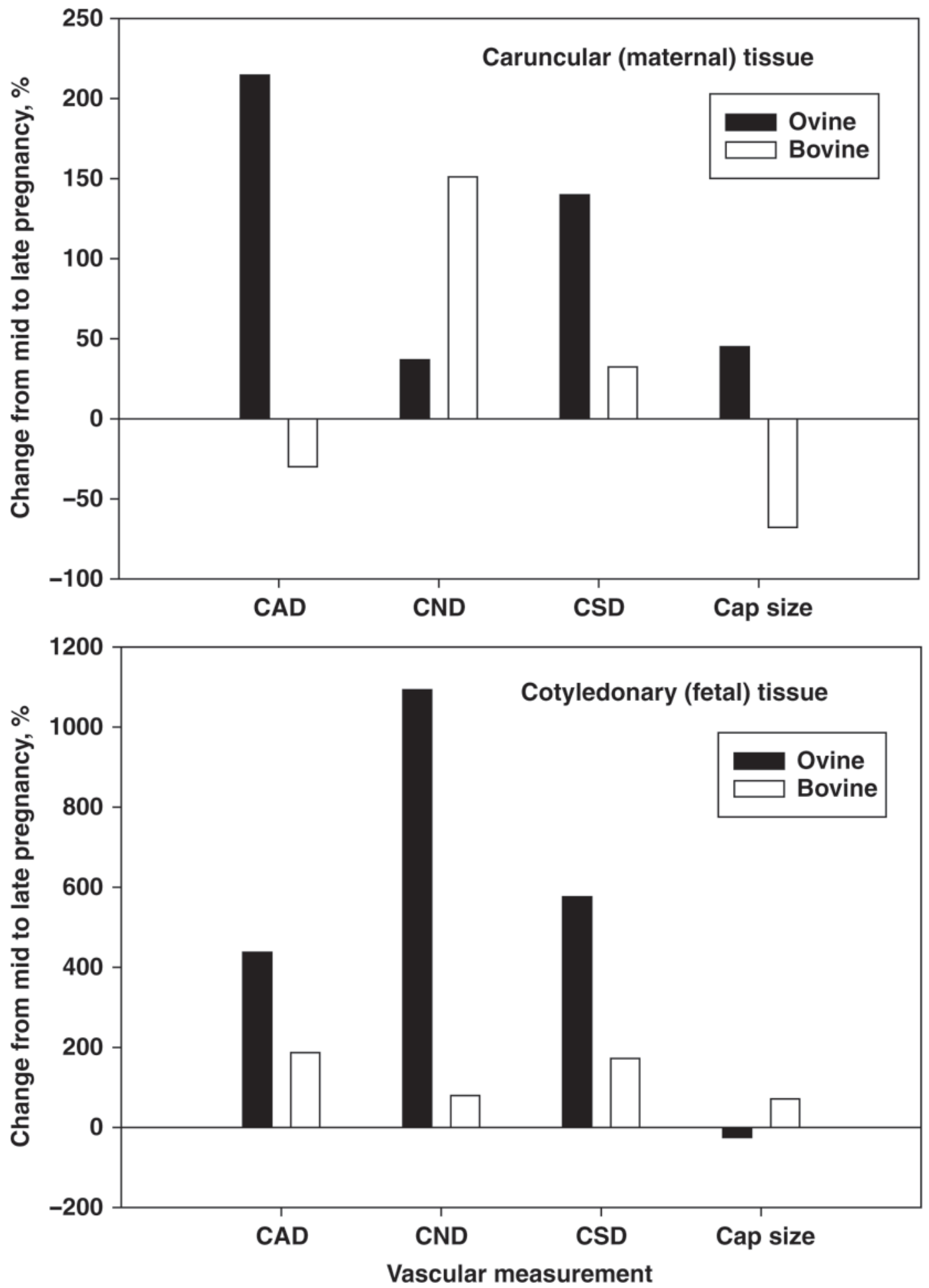

Figure 1. Comparison of percentage changes in capillary vascularity from mid- to late pregnancy in sheep (d 50 to 140; black bars) and cattle (d 125 to 250; white bars). CAD = capillary area density; CND = capillary number density; CSD = capillary surface density; Cap size = capillary size. Ovine data are adapted from Borowicz et al. (2007) and bovine data are adapted from Vonnahme et al. (2007). 
In cows, caruncular CAD decreased by $30 \%$ and capillary size decreased by $68 \%$, whereas CND and CSD increased by 151 and $32 \%$ from d 125 to 250 of gestation in animals fed adequately (Vonnahme et al., 2007; Figure 1). Furthermore, cotyledonary CAD, CND, CSD, and capillary size increased by $186,80,172$, and $71 \%$ from d 125 to 250 of gestation, respectively. Thus, the pattern of placental angiogenesis, particularly in the maternal tissue, appears to differ between cows and sheep; therefore, caution must be used when comparing the responses to altered nutrition during pregnancy between these 2 species.

Although maternal nutrient delivery during pregnancy has been shown to program the growth and development of the fetus, both during pregnancy and later into adult life, it appears that maternal nutrition also programs the development of the placenta. Development of the placental vascular bed is imperative to support the growth and development of the fetus. Although nutrient restriction from d 30 to 125 in cows did not alter the vascular architecture of the bovine placenta, placental function must have been altered as fetal weight was reduced. It appears that realimentation after approximately $90 \mathrm{~d}$ of nutrient restriction is the stimulus for altering not only placental vascularity and development, but also placental function in the cow (Vonnahme et al., 2004a,b). Therefore, future studies relating changes in vasculature architecture to placental function and uteroplacental blood flow in cattle is warranted.

Adequate uteroplacental blood flow is critical for normal fetal growth. Therefore, experimental conditions designed to investigate fetal growth retardation and placental insufficiency, be it through overnutrition, nutrient restriction, hyperthermia, or high altitude, commonly share reduced uterine and umbilical blood flows (Reynolds et al., 2006). Interestingly, many of these studies have investigated angiogenic factors and vasoactive compounds, including nitric oxide (NO). Nitric oxide is an endothelium-derived vasorelaxing factor that plays a key role in regulating uteroplacental blood flow (Bird et al., 2003). Protein supplementation in the ewe may influence blood flow by specific AA. Arginine, in particular, is a common substrate for $\mathrm{NO}$ and polyamine synthases via NO synthase. Results suggest that the abundance of arginine and associated arginine-related AA in fetal fluids of sheep are associated with greater NO synthase expression (Kwon et al., 2003, 2004; Wu and Self, 2005). In pigs, dietary protein deficiency reduced availability of arginine in maternal plasma, fetal plasma, and fetal fluids (Wu and Morris, 1998; Wu et al., 1998). Similarly, reduced arginine in ovine fetal fluids during mid-pregnancy from globally restricted ewes has been reported (Kwon et al., 2004). Arginine supplementation, through enhanced NO synthesis, has been shown to reduce fat mass in diabetic rats (Fu et al., 2005). Numerous pathways, including reduced lipid synthesis, increased lipolysis, increased substrate utilization, and increased oxidative phosphorylation (Jobgen et al., 2006), potentially affect this change. Research provides evidence that maternal undernutrition can increase adiposity of the offspring (Bispham et al., 2003), indicating a fetal programming effect that may be related to the arginine-NO axis (Wu et al., 2006). Assuming NO can facilitate increased lipid synthesis, preadipocyte recruitment may be enhanced, increasing the propensity for obesity or abnormal adiposity (Wu et al., 2006).

\section{Fetal Organogenesis}

Fetal organogenesis occurs simultaneously with placental development. In the beef fetus, a heartbeat is apparent as early as 21 to $22 \mathrm{~d}$ postovulation. Limb development occurs as early as d 25 of pregnancy, followed by a sequential development of other organs, including the pancreas, liver, adrenals, lungs, thyroid, spleen, brain, thymus, and kidneys (Hubbert et al., 1972). By d 45 , testicles of male calves are being developed, followed shortly thereafter by ovarian development occurring by d 50 to 60 of gestation. As the growth trajectories for these tissues vary, each tissue is susceptible to suboptimal conditions (e.g., maternal undernutrition) at different periods.

\section{Fetal Muscle Development}

Skeletal muscle has a lower priority in nutrient partitioning compared with the brain and heart in response to challenges to the fetus during development, rendering it particularly vulnerable to nutrient deficiency (Bauman et al., 1982; Close and Pettigrew, 1990). The fetal period is crucial for skeletal muscle development, because no net increase in the number of muscle fibers occurs after birth (Glore and Layman, 1983; Greenwood et al., 2000; Nissen et al., 2003). Results indicate that protein supplementation of the dam may increase calf birth weight and potentially alter fetal muscle growth (Larson et al., 2009). Greenwood et al. (2004) demonstrated that steers from cows nutritionally restricted during gestation had reduced BW and carcass weights at $30 \mathrm{mo}$ of age compared with steers from cows fed adequately. Interestingly, retail yield on a carcass weight basis was greater in steers from NR cows, indicating there was not an increased propensity for carcass fatness as a consequence of nutritional restriction in utero, similar to the results of Larson et al. (2009).

Studies with various mammals have shown that maternal undernutrition during gestation can significantly reduce the number of both muscle fibers and nuclei in the offspring (Bedi et al., 1982; Wilson et al., 1988; Ward and Stickland, 1991). For example, fewer fast glycolytic fibers were present in semitendinosus muscle of progeny from sows fed a high-energy diet than progeny from sows fed a low-energy diet during the first $50 \mathrm{~d}$ of gestation (Bee, 2004). In addition, progeny of sows fed a high-energy diet grew slower, had smaller feed-to-gain ratios, and had a greater percentage of adipose tissue than offspring from sows fed a low-energy diet during 
the first $50 \mathrm{~d}$ of gestation (Bee, 2004). A contrasting study (Bayol et al., 2004) in mice found restricted diets did not affect muscle fiber number or mRNA for myostatin or a myogenic regulatory transcription factor. Therefore, muscle fiber type development may be affected by nutritional state, depending on the energy needs of the muscle and species. Nutrient restriction from early to mid-gestation results in a reduction of fetal skeletal muscle fibers, which may be related to a downregulation of mammalian target of rapamycin signaling (Zhu et al., 2006). The mammalian target of rapamycin pathway is believed to mediate nutrient signals such as AA sufficiency (Fumagalli and Thomas, 2000; Gringras et al., 2001) and provides a link between nutritional levels and skeletal muscle development (Erbay et al., 2003).

\section{Reproductive Development}

Maternal diet can affect fetal reproductive tissues. Grazul-Bilska et al. (2009) fed ewes 60 or $100 \%$ of NRC recommendations from d 50 to 135 of gestation. Fetal ovaries were collected on d 135 of gestation and analyzed for cellular proliferation by using proliferating cell nuclear antigen. Interestingly, fetal ovaries from ewes experiencing a $60 \%$ nutrient restriction had a decreased cellular proliferation rate in primordial follicles compared with ovaries from fetuses of adequately fed ewes (Grazul-Bilska et al., 2009). This decreased proliferation in the primordial follicle may affect future follicular activity, fertility, and reproductive longevity of the female offspring. Unfortunately, their results did not indicate the reproductive success of these offspring. It was proposed previously that maternal protein supplementation may affect oocyte quality or early embryonic formation, resulting in fewer calves born during the first $21 \mathrm{~d}$ of the calving season (Martin et al., 2007). It was also noted that dams supplemented with protein during the last one-third of pregnancy gave birth to heifer calves that subsequently had increased pregnancy rate compared with heifers from nonsupplemented dams (Martin et al., 2007). Fewer heifers from nonsupplemented dams attained puberty before the first breeding season compared with heifers from supplemented cows in a subsequent study (Funston et al., 2008). Additionally, in rats whose dams were protein restricted during pregnancy, female pups had a delay to vaginal opening (i.e., puberty) and time to first estrus compared with control dams (Guzman et al., 2006).

\section{Cardiopulmonary Development}

Feeding pregnant rats a low-protein diet results in lifelong increases in blood pressure in the offspring (Langley and Jackson, 1994). Early chronic undernutrition results in a significant increase in fetal blood pressure (Murotsuki et al., 1997). Increases in fetal blood pressure are known to result in alterations in lung vascular remodeling in association with myocardial hypertrophy in the rat (Fabris and Pato, 2001). Fabris and Pato (2001) speculated that lung growth in late gestation is adversely affected by pulmonary hypertension. The pulmonary circulation develops concomitantly with distal lung air space growth during late gestation and early postnatal life (deMello and Reid, 1991). Wohrley et al. (1995) demonstrated that hypoxic conditions selectively induce the proliferation of smooth muscle cells associated with the pulmonary arteries in neonatal calves with pulmonary hypertension. The precise relationship between alveolar and vascular development during fetal and early postnatal life and the mechanisms coordinating lung vascular growth and alveolarization are uncertain. However, VEGF, produced from airway epithelial cells, plays a major role in vascular growth and development during fetal life (Zeng et al., 1998). These findings indicate that mechanisms may exist to link lung vascular development with alveolar growth, further indicating that disruption of normal vascularization may contribute to altered alveolarization and thus altered lung function. Bovine respiratory diseases make up the majority of illness and death loss in the feedlot segment. Historically, 15 to $45 \%$ of feedlot cattle have been affected with bovine respiratory disease (BRD), with 1 to $5 \%$ mortality of total cattle placed on feed as a result of BRD (Kelly and Janzen, 1986). Respiratory disease alone accounts for $44.1 \%$ of deaths in beef feedlot cattle (Vogel and Parrott, 1994). It is possible that gestational nutrient restriction could increase the susceptibility of cattle to respiratory disease during later life.

\section{Metabolic Function}

Rats whose mothers were fed a diet with a low ratio of protein to energy during pregnancy demonstrated permanently altered glucose production and utilization and associated insulin secretion (Desai et al., 1995). More specifically, Fowden and Hill (2001) demonstrated that changes in the intrauterine nutritional environment caused alterations in the structure and function of the pancreatic islets in rodents. Altered pancreatic islets have lifelong effects and predispose the animal to glucose intolerance and diabetes. Intrauterine programming of the endocrine pancreas in ruminant species is less established at present; however, it has recently been demonstrated that ewe lambs from restricted dams have altered glucose metabolism (Effertz et al., 2007). Furthermore, male lambs from early-gestation NR ewes display hyperglycemia and altered insulin secretion patterns (Ford et al., 2007). Additionally, lambs from ewes restricted in late gestation appear to be insulin resistant and have a reduction in GLUT4 expression in adipose tissue with increased adipose mass (Gardner et al., 2005). The relative insulin resistance of the adult ruminant compared with other species makes it difficult to establish whether fetal changes in islet development have long-term consequences. Alterations in pancreatic function are difficult to assess in grazing cattle because 
most of the energetic needs are supplied from nonglucose sources; therefore, insulin plays a relatively small role in grazing ruminant energetics. However, Murphy et al. (2000) reported that small changes in nutrient metabolism (determined via response to a glucose challenge) were sufficient to influence milk production in the dairy cow, which derives more energetic needs from glucose. Further research in concentrate-fed animals is needed to determine pancreatic function.

\section{Intrauterine Growth and Birth Weight}

Most early work investigating the effects of maternal nutrition in cattle studied the later part of gestation. Because most fetal growth occurs in the later part of gestation, researchers hypothesized that the effects of variation in nutrient intake would have greater effects than in early pregnancy. Many studies report the effects of protein and energy deficiency on calf birth weight (Holland and Odde, 1991). When cows were provided a protein supplement during the last one-third of pregnancy, birth weights did not differ from those of nonsupplemented dams (Martin et al., 2007). However, recent work indicates that protein supplementation during late gestation, as well as increased global nutrient supply throughout gestation, may increase calf birth weight (Larson et al., 2009). Nutrient restriction during early pregnancy may have different effects on birth weight. Ewes restricted during early pregnancy (i.e., d 0 to 39) gave birth to heavier lambs than nonrestricted counterparts (Munoz et al., 2008). These ewes were realimented during late gestation, which most likely allowed these lambs to compensate for early restriction in terms of fetal growth. It is interesting that maternal nutrition, even during a period of minimal fetal growth, can program the fetus, possibly by alterations in placental function.

\section{POSTNATAL DEVELOPMENT IN RESPONSE TO FETAL PROGRAMMING: NEONATE HEALTH AND SURVIVAL}

Effects of maternal nutrition during pregnancy on the offspring may have confounded effects on neonatal development because maternal diet also affects the mammary gland and colostrum yield. In a recent study, lambs were immediately separated from their dams and fed artificial colostrum, and concentrations of IgG were measured $24 \mathrm{~h}$ later. Offspring from undernourished dams had increased IgG transfer, whereas lambs from overnourished ewes had decreased IgG transfer compared with control-fed dams (Hammer et al., 2007). This indicates that the fetal gastrointestinal system in NR animals may be programmed to be more efficient in extracting nutrients, specifically large molecules such as immunoglobulins immediately postnatal. Colostrum quantity, IgG amounts, total fat, and protein were decreased in both the undernourished and the overnour- ished ewes (Swanson et al., 2008). Further, mammary gland weight was reduced in undernourished ewes and in overnourished ewes when expressed as a percentage of BW. This indicates that lamb health is affected directly by maternal diet during pregnancy and through alterations in the mammary system.

Corah et al. (1975) reported that pregnant cows fed $70 \%$ of their calculated energy requirements during the last $90 \mathrm{~d}$ of gestation produced calves with increased morbidity and mortality rates. Research conducted at Colorado State University (see review by Odde, 1988) investigated the relationship between precalving nutrition and disease susceptibility in the neonatal calf. First-calf heifers produce calves that have decreased concentrations of serum immunoglobulins at $24 \mathrm{~h}$ of age compared with calves born to cows that are $3 \mathrm{yr}$ old and older. This occurs even though colostral immunoglobulin concentrations are similar for these 2 age groups. The increased disease susceptibility observed in calves born to first-calf heifers is likely due to reduced volumes of colostrum produced by first-calf heifers, although decreased calf vigor because of increased dystocia may also contribute. Calves born to thin (BCS 3 and 4) 2-yr-old heifers are less vigorous and have reduced serum immunoglobulin concentrations at $24 \mathrm{~h}$ of age. Morbidity in neonatal calves not only increases the risk of mortality, but it also results in reduced performance. Wittum et al. (1994) reported that general morbidity during the neonatal period resulted in a $15.6-\mathrm{kg}$ reduction in weaning weight. Respiratory conditions and diarrhea during the neonatal period resulted in 16.5and $10.7-\mathrm{kg}$ reductions in weaning weight, respectively. Heat production of the neonate is an important factor in survivability, particularly for calves born in cold environments. First-calf heifers restricted in either protein (Carstens et al., 1987) or energy (Ridder et al., 1991) during the last third of pregnancy gave birth to calves with reduced ability to produce heat shortly after birth. This likely results in calves that are more susceptible to cold stress. Lambs from early-gestation NR ewes, in addition to being heavier at birth, had greater IgG concentrations in serum and greater survival to weaning (Munoz et al., 2008). Previous results indicate a fetal programming effect on lamb and calf health in response to protein, vitamin, and mineral supplementation of the dam during mid- and late gestation (Boland et al., 2006). These effects may be the result of enhanced IgG supply or an alteration of fetal absorption of IgG and nutrients. However, this area requires further study.

\section{EFFECT OF SPECIFIC NUTRIENTS ON FETAL DEVELOPMENT AND POSTNATAL PERFORMANCE}

\section{Energy or Concentrate Supplementation}

A large proportion of nonstructural carbohydrates in the ruminant diet are fermented to propionate in the rumen. Propionate is largely converted to glucose, 
Table 1. Effect of maternal protein supplementation on heifer progeny performance

\begin{tabular}{|c|c|c|c|c|}
\hline \multirow[b]{3}{*}{ Item } & \multicolumn{4}{|c|}{ Dietary treatment } \\
\hline & \multicolumn{2}{|c|}{ Martin et al. $(2007)^{1}$} & \multicolumn{2}{|c|}{ Funston et al. $(2008)^{2}$} \\
\hline & NS & SUP & NS & SUP \\
\hline Weaning BW, kg & 207 & 212 & $223^{\mathrm{a}}$ & $232^{\mathrm{b}}$ \\
\hline DMI, $\mathrm{kg} / \mathrm{d}$ & 6.50 & 6.75 & 7.29 & 7.30 \\
\hline $\mathrm{ADG}, \mathrm{kg} / \mathrm{d}$ & 0.41 & 0.40 & 0.81 & 0.77 \\
\hline Residual feed intake, $\mathrm{kg} / \mathrm{d}$ & -0.12 & 0.07 & $-0.50^{\mathrm{a}}$ & $0.01^{\mathrm{b}}$ \\
\hline Age at puberty, d & 334 & 339 & $365^{\mathrm{x}}$ & $352^{\mathrm{y}}$ \\
\hline Pregnant, $\%$ & $80^{\mathrm{a}}$ & $93^{\mathrm{b}}$ & 83 & 90 \\
\hline \multicolumn{5}{|c|}{$\begin{array}{l}{ }^{\mathrm{a}, \mathrm{b}} \text { Means within a study with different superscripts differ }(P \leq 0.05) \text {. } \\
{ }^{\mathrm{x}, \mathrm{y}} \text { Means within a study with different superscripts differ }(P \leq 0.10) \text {. } \\
{ }^{1} \mathrm{NS}=\text { dams did not receive protein supplement while grazing dormant Sandhills range during the last third } \\
\text { of gestation; SUP = dams were supplemented } 3 \text { times per week with the equivalent of } 0.45 \mathrm{~kg} / \mathrm{d} \text { of a } 42 \% \mathrm{CP} \\
\text { cake (DM basis) while grazing dormant Sandhills range during the last third of gestation. } \\
{ }^{2} \mathrm{NS}=\text { dams did not receive protein supplement while grazing dormant Sandhills range or corn residue dur- } \\
\text { ing the last third of gestation; SUP = dams were supplemented } 3 \text { times per week with the equivalent of } 0.45 \\
\mathrm{~kg} / \mathrm{d} \text { of a } 28 \% \mathrm{CP} \text { cake (DM basis) while grazing dormant Sandhills range or corn residue during the last third } \\
\text { of gestation. }\end{array}$} \\
\hline
\end{tabular}

via gluconeogenesis, in the liver. Glucose is an essential substrate for fetal development and growth. Thus, supplementation with nonstructural carbohydrates may have beneficial effects on fetal development under NR conditions. Providing first-calf heifers and mature cows with a high-energy diet $100 \mathrm{~d}$ prepartum increased BW before parturition and calf birth weight (Corah et al., 1975). In that study, approximately $19 \%$ more calves from mature cows offered a low-energy diet were treated for scours, and subsequent weaning weight was greater for calves from cows consuming the high-energy diet. Restricting beef cows to $57 \%$ of the NRC requirement for energy and protein for the last $90 \mathrm{~d}$ of gestation reduced maternal BW and BCS before calving (Hough et al., 1990). Interestingly, colostrum IgG concentration and calf serum IgG concentration were unaffected by dam nutrition; however, when colostrum from restricted dams was consumed by calves from nonrestricted dams, those calves had less serum IgG. There is potentially a difference in small intestinal nutrient transfer efficiency between calves from restricted vs. nonrestricted dams, similar to lambs from NR ewes.

Pregnant ewes were restricted or offered adequate nutrition between 28 and $80 \mathrm{~d}$ of gestation (Bispham et al., 2003). Plasma leptin did not exhibit the characteristic increase during pregnancy when ewes were restricted. This is particularly intriguing because leptin is considered a "thrifty" gene product, and polymorphisms in the gene or the receptor could change how and when fat is deposited. Adipose tissue weight was greater at parturition for lambs from restricted dams. Perhaps more interesting, leptin mRNA and adipose tissue mass were actually reduced in lambs from dams offered adequate nutrition throughout gestation.

\section{Protein Supplementation}

Limited data are available on the effect of protein supplementation during late gestation in beef cattle.
Most data were collected using winter grazing systems (Stalker et al., 2006, 2007; Martin et al., 2007; Funston et al., 2008; Larson et al., 2009). Protein supplementation to beef cows may take many forms; however, providing added ruminally undegradable protein has the greatest chance of correcting a nutrient deficiency because forage usually provides adequate ruminally degradable protein.

Regarding female progeny (Table 1), protein supplementation of the dam increased weaning weight of the calves without a change in birth weight, and this change persisted through pregnancy diagnosis and before calving. More interestingly, age at puberty was not greatly affected, but protein supplementation of the dam increased the pregnancy rate of the heifer calves (Martin et al., 2007). However, in a subsequent study, more heifers from protein-supplemented dams were pubertal before breeding, possibly affecting pregnancy rate (Funston et al., 2008). Heifers from protein-supplemented dams may have greater DMI and are less efficient in terms of residual feed intake compared with heifers from nonsupplemented dams. This provides evidence for an efficiency adjustment in response to fetal environment, whereby heifer fetuses exposed to restricted nutrients (i.e., nonsupplemented dams) during gestation actually become more efficient in later life.

Steer progeny from the protein-supplemented cows are also heavier at weaning and have heavier carcass weights (Table 2). Similar to heifer mates, steers from protein-supplemented dams may also consume more feed. However, feed efficiency does not appear to be negatively influenced because there is a concomitant increase in daily BW gain. Protein supplementation of the dam also increases the intramuscular fat content of the steer, leading to a more valuable carcass. Results also indicate that steers from protein-supplemented dams have a greater overall percentage of body fat (Larson et al., 2009). 
Table 2. Effect of maternal protein supplementation on steer progeny performance

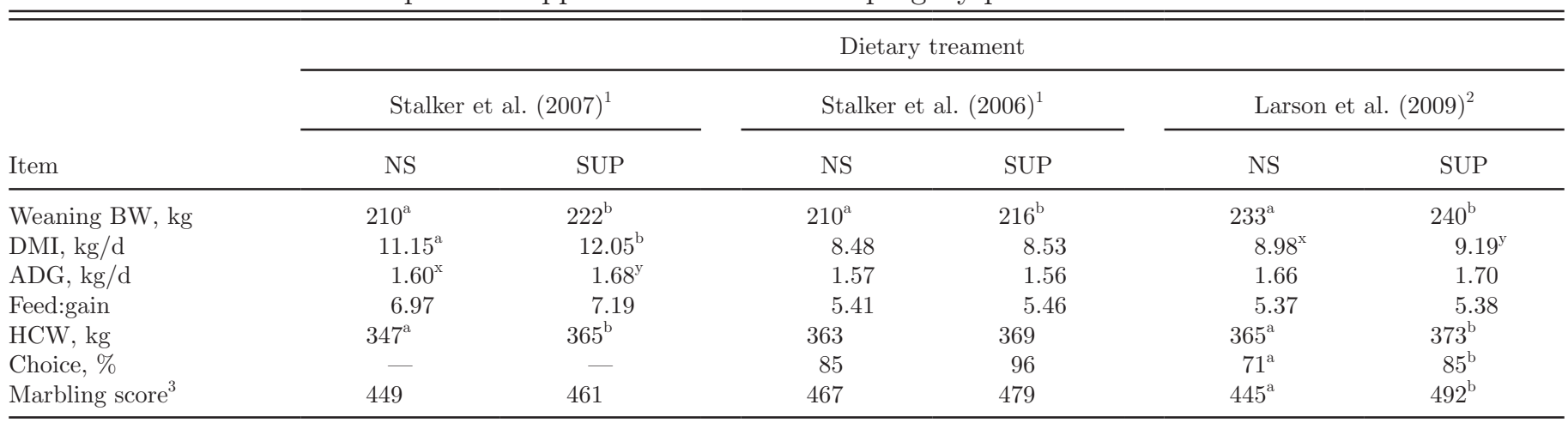

${ }^{\mathrm{a}, \mathrm{b}}$ Means within a study with different superscripts differ $(P \leq 0.05)$.

${ }^{\mathrm{x}, \mathrm{y}}$ Means within a study with different superscripts differ $(P \leq 0.10)$.

${ }^{1} \mathrm{NS}=$ dams did not receive protein supplement while grazing dormant Sandhills range during the last third of gestation; SUP $=$ dams were supplemented 3 times per week with the equivalent of $0.45 \mathrm{~kg} / \mathrm{d}$ of a $42 \% \mathrm{CP}$ cake (DM basis) while grazing dormant Sandhills range during the last third of gestation.

${ }^{2} \mathrm{NS}=$ dams did not receive protein supplement while grazing dormant Sandhills range or corn residue during the last third of gestation; SUP = dams were supplemented 3 times per week with the equivalent of $0.45 \mathrm{~kg} / \mathrm{d}$ of a $28 \% \mathrm{CP}$ cake (DM basis) while grazing dormant Sandhills range or corn residue during the last third of gestation.

${ }^{3}$ Where $400=$ Small $^{0}$.

Because fetal growth progresses rapidly during the last third of gestation, added nutrition during this period may alter the site of nutrient deposition. Early work by Smith and Crouse (1984) indicated that glucose is the primary substrate utilized by intramuscular adipocytes. Because glucose is a primary substrate of intramuscular adipocytes and protein supplementation during late gestation increased the percentage of steer grading choice, the supply of glucogenic AA from protein supplementation is a potential mediator of this change.

Although it does not necessarily represent supplemental protein, grazing cows on improved pasture increases availability of protein as well as energy. At approximately $140 \mathrm{~d}$ of gestation, cows were assigned to graze either native or improved pasture (Underwood et al., 2008). Steers from the cows grazing improved pasture gained more BW during the finishing period and were heavier at slaughter, with greater HCW (Underwood et al., 2008). The steers from cows grazing improved pasture were also fatter at slaughter. The increase in fat depth resulted from more adipocytes per unit of area of subcutaneous fat. If one assumes that enhanced early nutrition can drive the designation of stem cells to a preadipocyte fate, then increased fat with enhanced fetal nutrient supply seems plausible. Smith and Crouse (1984) also found that acetate is the primary substrate utilized by subcutaneous adipocytes. Thus, because the diet in the previously described study included no concentrate, then the major product of fermentation will be acetate. Therefore, the increased acetate product may have increased recruitment of stem cells to the preadipocyte fate, leading to increased total body fatness later in life.

Guinea pigs provided a diet at $60 \%$ of ad libitum intake during gestation gave birth to pups with a decrease in total muscle fiber development, mostly because of a decrease in secondary muscle fibers. Protein supplementation negated this change in muscle development and the number of secondary muscle fibers was similar to controls (Dwyer and Stickland, 1994), thereby providing evidence that protein supplementation of the dam may enhance BW gain by increasing the muscle fiber number, which is determined before birth.

Recent results indicate that late-gestation maternal protein supplementation may affect carcass quality by affecting calf health. Protein supplementation did not affect calf health from birth until weaning; however, more calves from non-protein-supplemented cows received treatment for BRD between weaning and slaughter (Larson et al., 2009). This may have resulted from various causes. Neonatal colostrum and IgG supply may influence feedlot health. Calves receiving inadequate passive immunity from colostrum have a decreased plasma protein concentration and are more prone to becoming sick during the feedlot phase (Wittum and Perino, 1995). Stalker et al. (2006) reported that protein supplementation did not influence IgG titers 24 and $48 \mathrm{~h}$ after birth; however, they did not report an effect on calf health. Results also indicate that calves from dams receiving protein supplement had improved carcass quality. However, as previously indicated, lambs from undernourished dams had increased serum IgG concentration, implying that IgG transfer was improved. Studies have demonstrated that calves receiving treatment for BRD have lower quality grades than steers not receiving treatment (Gardner et al., 1999; Busby et al., 2004). Thus, protein supplementation may influence carcass quality through calf health.

\section{Summary and Conclusions}

Livestock are often produced in systems in which resources may be limiting in quantity or quality during 
periods of the production cycle. It is important to understand when such deficiencies may affect the performance of both the dam and developing fetus. There is a rapidly developing body of literature indicating that nutritional insufficiencies during fetal development may have implications for subsequent postnatal growth and development. Some of the factors affected include birth weight, health, growth, reproduction, carcass weight, and carcass quality. Timing of nutrient restriction during gestation appears to affect different physiological processes. Early-gestation restriction appears to affect placental development and alterations in vascularity, whereas later gestation restriction likely affects final development of organ systems or nutrient uptake by tissues important for growth and reproduction. The precise mechanisms by which nutrient restriction and specific nutrients influence postnatal growth and development are largely unknown and remain to be elucidated. Mitigating these negative effects involves nutritional management to provide supplemental nutrients when the basal diet is deficient and results in decreases in body condition. An alternative may be to manage body condition with specific management practices that allow the animal to achieve greater body condition before being exposed to a limited-nutrient environment. Possibilities may include early weaning or changing the time of breeding, and thus parturition.

\section{LITERATURE CITED}

Barker, D. J. P., C. N. Martyn, C. Osmond, C. N. Hales, and C. H. D. Fall. 1993. Growth in utero and serum cholesterol concentration in adult life. BMJ 307:1524-1527.

Bauman, D. E., J. H. Eisemann, and W. B. Currie. 1982. Hormonal effects on partitioning of nutrients for tissue growth: Role of growth hormone and prolactin. Fed. Proc. 41:2538-2544.

Bayol, S., D. Jones, G. Goldspink, and N. C. Strickland. 2004. The influence of undernutrition during gestation on skeletal muscle cellularity and on the expression of genes that control muscle growth. Br. J. Nutr. 91:331-339.

Bedi, K. S., A. R. Birzgalis, M. Mahon, J. L. Smart, and A. C. Wareham. 1982. Early life undernutrition in rats. 1. Quantitative histology of skeletal muscles from underfed young and refed adult animals. Br. J. Nutr. 47:417-431.

Bee, G. 2004. Effect of early gestation feeding, birth weight, and gender of progeny on muscle fiber characteristics of pigs at slaughter. J. Anim. Sci. 82:826-836.

Bird, I. M., L. Zhang, and R. R. Magness. 2003. Possible mechanisms underlying pregnancy-induced changes in uterine artery endothelial function. Am. J. Physiol. Regul. Integr. Comp. Physiol. 284:R245-R258.

Bispham, J., G. S. Gopalakrishanan, J. Dandrea, V. Wilson, H. Budge, D. H. Keisler, F. Broughton Pipkin, T. Stephenson, and M. E. Symonds. 2003. Maternal endocrine adaptation throughout pregnancy to nutritional manipulation: Consequences for maternal plasma leptin and cortisol and the programming of fetal adipose tissue development. Endocrinology 144:35753585 .

Boland, T. M., J. J. Callan, P. O. Brophy, P. J. Quinn, and T. F. Crosby. 2006. Lamb serum vitamin $\mathrm{E}$ and immunoglobulin $\mathrm{G}$ concentrations in response to various maternal mineral and iodine supplementation regimens. Anim. Sci. 82:319-325.

Borowicz, P. P., D. R. Arnold, M. L. Johnson, A. T. Grazul-Bilska, D. A. Redmer, and L. P. Reynolds. 2007. Placental growth throughout the last two-thirds of pregnancy in sheep: Vascular development and angiogenic factor expression. Biol. Reprod. 76:259-267.

Busby, W. D., D. R. Stohbehn, P. Beedle, and L. R. Corah. 2004. Effect of postweaning health on feedlot performance and quality grade. A.S. Leaflet R1855. Iowa State Univ., Ames.

Carstens, G. E., D. E. Johnson, M. D. Holand, and K. G. Odde. 1987. Effects of prepartum protein nutrition and birth weight on basal metabolism in bovine neonates. J. Anim. Sci. 65:745751.

Close, W. H., and J. F. Pettigrew. 1990. Mathematical models of sow reproduction. J. Reprod. Fertil. Suppl. 40:83-88.

Corah, L. R., T. G. Dunn, and C. C. Kaltenbach. 1975. Influence of prepartum nutrition on the reproductive performance of beef females and the performance of their progeny. J. Anim. Sci. 41:819-824.

deMello, D. E., and L. M. Reid. 1991. Pre- and postnatal development of the pulmonary circulation. Pages 36-54 in Basic Mechanisms of Pediatric Respiratory Disease: Cellular and Integrative.V. Chernick and R. B. Mellins, ed. Decker, Philadelphia, PA.

Desai, M., N. Crowther, S. E. Ozanne, A. Lucas, and C. N. Hales. 1995. Adult glucose and lipid metabolism may be programmed during fetal life. Biochem. Soc. Trans. 23:331-335.

Dwyer, C. M., and N. C. Stickland. 1994. Supplementation of a restricted maternal diet with protein or carbohydrate alone prevents a reduction in fetal muscle fibre number in the guinea-pig. Br. J. Nutr. 72:173-180.

Effertz, C. M., J. S. Caton, C. J. Hammer, J. S. Luther, T. L. Neville, J. J. Reed, D. A. Redmer, L. P. Reynolds, and K. A. Vonnahme. 2007. Glucose tolerance of offspring born from ewes receiving differing nutritional levels during pregnancy. J. Anim. Sci. 85(Suppl. 2):79. (Abstr.)

Erbay, E., I. H. Park, P. D. Nuzzi, C. J. Schoenherr, and J. Chen. 2003. IGF-II transcription in skeletal myogenesis is controlled by mTOR and nutrients. J. Cell Biol. 163:931-936.

Fabris, V. E., and M. D. Pato. 2001. Progressive lung and cardiac changes associated with pulmonary hypertension in the fetal rat. Pediatr. Pulmonol. 31:344-353.

Foote, W. C., A. L. Pope, C. R. Earl, A. B. Chapman, and L. E. Casida. 1958. Reproduction in the yearling ewe as affected by breed and sequence of feeding levels: II. Effects on fetal development. J. Anim. Sci. 18:463-474.

Ford, S. P., B. W. Hess, M. M. Schwope, M. J. Nijland, J. S. Gilbert, K. A. Vonnahme, W. J. Means, H. Han, and P. W. Nathanielsz. 2007. Maternal undernutrition during early to mid-gestation in the ewe results in altered growth, adiposity, and glucose tolerance in male offspring. J. Anim. Sci. 85:1285-1294.

Fowden, A. L., and D. J. Hill. 2001. Intra-uterine programming of the endocrine pancreas. Br. Med. Bull. 60:123-142.

Fu, W. J., T. E. Haynes, R. Kohli, J. Hu, W. Shi, T. E. Spencer, R. J. Carroll, C. J. Meininger, and G. Wu. 2005. Dietary Larginine supplementation reduced fat mass in Zucker diabetic fatty rats. J. Nutr. 135:714-721.

Fumagalli, S., and G. Thomas. 2000. S6 phosphorylation and signal transduction. Pages 695-718 in Translational Control of Gene Expression. N. Sonenbery, J. W. B. Hershey, and M. B. Mathews, ed. Cold Spring Harbor Laboratory Press, Cold Spring Harbor, NY.

Funston, R. N., J. L. Martin, D. C. Adams, and D. M. Larson. 2008. Effects of winter grazing system and supplementation during late gestation on performance of beef cows and progeny. Proc. West. Sec. Am. Soc. Anim. Sci. 59:102-105.

Gardner, B. A., H. G. Dolezal, L. K. Bryant, F. N. Owens, and R. A. Smith. 1999. Health of finishing steers: Effects on performance, carcass traits, and meat tenderness. J. Anim. Sci. 77:3168-3175.

Gardner, D. S., K. Tingey, B. W. M. Van Bon, S. E. Ozanne, V. Wilson, J. Dandrea, D. H. Keisler, T. Stephenson, and M. E. Symonds. 2005. Programming of glucose-insulin metabolism in adult sheep after maternal undernutrition. Am. J. Physiol. Regul. Integr. Comp. Physiol. 289:R947-R954. 
Glore, S. R., and D. K. Layman. 1983. Cellular growth of skeletal muscle in weanling rats during dietary restrictions. Growth 47:403-410.

Godfrey, K. M., and D. J. P. Barker. 2000. Fetal nutrition and adult disease. Am. J. Clin. Nutr. 71(Suppl.):1344S-1352S.

Grazul-Bilska, A. T., J. S. Caton, W. Arndt, K. Burchill, C. Thorson, E. Boroczyk, J. J. Bilski, D. A. Redmer, L. P. Reynolds, and K. A. Vonnahme. 2009. Cellular proliferation and vascularization in ovine fetal ovaries: Effects of undernutrition and selenium in maternal diet. Reproduction 137:699-707.

Greenwood, P. L., H. Hearnshaw, L. M. Cafe, D. W. Hennessy, and G. S. Harper. 2004. Nutrition in utero and pre-weaning has long term consequences for growth and size of Piedmontese and Wagyu-sired steers. J. Anim. Sci. 82(Suppl. 1):408. (Abstr.)

Greenwood, P. L., A. S. Hunt, J. W. Hermanson, and A. W. Bell. 2000. Effects of birth weight and postnatal nutrition on neonatal sheep: II. Skeletal muscle growth and development. J. Anim. Sci. 78:50-61.

Gringras, A.-C., B. Raught, and N. Sonenberg. 2001. Regulation of translation initiation by FRAP/mTOR. Genes Dev. 15:807826.

Guzman, C., R. Cabrera, M. Cardenas, F. Larrea, P. W. Nathanielsz, and E. Zambrano. 2006. Protein restriction during fetal and neonatal development in the rat alters reproductive function and accelerates reproductive ageing in female progeny. J. Physiol. 572:97-108.

Hammer, C. J., K. A. Vonnahme, J. B. Taylor, D. A. Redmer, J. S. Luther, T. L. Neville, J. J. Reed, J. S. Caton, and L. P. Reynolds. 2007. Effects of maternal nutrition and selenium supplementation on absorption of IgG and survival of lambs. J. Anim. Sci. 85(Suppl. 1):391. (Abstr.)

Heasman, L., L. Clarke, K. Firth, T. Stephenson, and M. E. Symonds. 1998. Influence of restricted maternal nutrition in early to mid gestation on placental and fetal development at term in sheep. Pediatr. Res. 44:546-551.

Holland, M. D., and K. G. Odde. 1991. Factors affecting calf birth weight: A review. Theriogenology 38:769-798.

Hough, R. L., F. D. McCarthy, H. D. Kent, D. E. Eversole, and M. L. Wahlberg. 1990. Influence of nutritional restriction during late gestation on production measures and passive immunity in beef cattle. J. Anim. Sci. 68:2622-2627.

Hubbert, W. T., O. H. V. Stalheim, and G. D. Booth. 1972. Changes in organ weights and fluid volumes during growth of the bovine fetus. Growth 36:217-233.

Jobgen, W. S., S. K. Fried, W. J. Fu, C. J. Meininger, and G. Wu. 2006. Regulatory role for the arginine-nitric oxide pathway in metabolism of energy substrates. J. Nutr. Biochem. 17:571588.

Kelly, A. P., and E. D. Janzen. 1986. A review of morbidity rates and disease occurrence in North American feedlot cattle. Can. Vet. J. 27:496-500.

Kwon, H., S. P. Ford, F. W. Bazer, T. E. Spencer, P. W. Nathanielsz, M. J. Nijland, B. W. Hess, and G. Wu. 2004. Maternal undernutrition reduces concentration of amino acids and polyamines in ovine maternal and fetal plasma and fetal fluids. Biol. Reprod. 71:901-908.

Kwon, H., G. Wu, F. W. Bazer, and T. E. Spencer. 2003. Developmental changes in polyamine levels and synthesis in the ovine conceptus. Biol. Reprod. 69:1626-1634.

Langley, S. C., and A. A. Jackson. 1994. Increased systolic blood pressure in adult rats induced by fetal exposure to maternal low protein diets. Clin. Sci. 86:217-222.

Larson, D. M., J. L. Martin, D. C. Adams, and R. N. Funston. 2009. Winter grazing system and supplementation during late gestation influence performance of beef cows and steer progeny. J. Anim. Sci. 87:1147-1155.

Martin, J. L., K. A. Vonnahme, D. C. Adams, G. P. Lardy, and R. N. Funston. 2007. Effects of dam nutrition on growth and reproductive performance of heifer calves. J. Anim. Sci. 85:841847.
McMullen, S., J. C. Osgerby, J. S. Milne, J. M. Wallace, and D. C. Wathes. 2005. The effects of acute nutrient restriction in the mid-gestational ewe on maternal and fetal nutrient status, the expression of placental growth factors and fetal growth. Placenta 26:25-33.

Meschia, G. 1983. Circulation to female reproductive organs. Pages 241-267 in Handbook of Physiology. Vol. 3. J. T. Shepherd and F. M. Abboud, ed. Am. Physiol. Soc., Bethesda, MD.

Munoz, C., A. F. Carson, M. A. McCoy, L. E. R. Dawson, N. E. Connell, and A. W. Gordon. 2008. Nutritional status of adult ewes during early and mid-pregnancy. 1. Effects of plane of nutrition on ewe reproduction and offspring performance to weaning. Animal 2:52-63.

Murotsuki, J., J. R. G. Challis, V. K. M. Han, J. Fraher, and R. Gagnon. 1997. Chronic fetal placental embolization and hypoxaemia cause hypertension and myocardial hypertrophy in fetal sheep. Am. J. Phys. 272:R201-R207.

Murphy, M., M. Arkerland, and K. Holtenius. 2000. Rumen fermentation in lactating cows selected for milk fat content fed two forage to concentrate ratios with hay or silage. J. Dairy Sci. 83:756-764.

Nissen, P. M., V. O. Danielson, P. F. Jorgensen, and N. Oksbjerg. 2003. Increased maternal nutrition of sows has no beneficial effects on muscle fiber number or postnatal growth and has no impact on the meat quality of the offspring. J. Anim. Sci. 81:3018-3027.

Odde, K. G. 1988. Survival of the neonatal calf. Vet. Clin. N. Am. Food Anim. Pract. 4:501-508.

Odorisio, T., C. Schietroma, M. L. Zaccaria, F. Cianfarani, C. Tiveron, L. Tatangelo, C. M. Failla, and G. Zambruno. 2002. Mice overexpressing placenta growth factor exhibit increased vascularization and vessel permeability. J. Cell Sci. 115:2559-2567.

Patten, B. M. 1964. Foundations of Embryology. 2nd ed. McGrawHill, New York, NY.

Peters, K. G., C. De Vries, and L. T. Williams. 1993. Vascular endothelial growth factor receptor expression during embryogenesis and tissue repair suggests a role in endothelial differentiation and blood vessel growth. Proc. Natl. Acad. Sci. USA 90:8915-8919.

Ramsey, E. M. 1982. The Placenta, Human and Animal. Praeger, New York, NY.

Reynolds, L. P., P. Borowicz, K. A. Vonnahme, M. L. Johnson, A. T. Grazul-Bilska, J. M. Wallace, J. S. Caton, and D. A. Redmer. 2005. Animal models of placental angiogenesis. Placenta 26:689-708.

Reynolds, L. P., J. S. Caton, D. A. Redmer, A. T. Grazul-Bilska, K. A. Vonnahme, P. P. Borowicz, J. S. Luther, J. M. Wallace, G. Wu, and T. E. Spencer. 2006. Evidence for altered placental blood flow and vascularity in compromised pregnancies. J. Physiol. 572:51-58.

Reynolds, L. P., C. L. Ferrell, D. A. Robertson, and J. Klindt. 1990. Growth hormone, insulin and glucose concentrations in bovine fetal and maternal plasmas at several stages of gestation. J. Anim. Sci. 68:725-733.

Reynolds, L. P., and D. A. Redmer. 1995. Utero-placental vascular development and placental function. J. Anim. Sci. 73:1839 1851.

Reynolds, L. P., and D. A. Redmer. 2001. Angiogenesis in the placenta. Biol. Reprod. 64:1033-1040.

Ridder, T. A., W. Young, K. A. Anderson, D. W. Lodman, M. D. Holland, D. E. Johnson, and K. G. Odde. 1991. Effects of prepartum energy nutrition and body condition on birth weight and basal metabolism in bovine neonates. Page 119 in CSU Beef Program Rep. Colorado State University, Fort Collins.

Robinson, J., S. Chidzanja, K. Kind, F. Lok, P. Owens, and J. Owen. 1995. Placental control of fetal growth. Reprod. Fertil. Dev. 7:333-344.

Robinson, J. J., I. McDonald, C. Fraser, and I. McHattie. 1977. Studies on reproduction in prolific ewes. I. Growth of the products of conception. J. Agric. Sci. Camb. 88:539-552. 
Smith, S. B., and J. D. Crouse. 1984. Relative contributions of acetate, lactate and glucose to lipogenesis in bovine intramuscular and subcutaneous adipose tissue. J. Nutr. 114:792-800.

Stalker, L. A., D. C. Adams, T. J. Klopfenstein, D. M. Feuz, and R. N. Funston. 2006. Effects of pre- and postpartum nutrition on reproduction in spring calving cows and calf feedlot performance. J. Anim. Sci. 84:2582-2589.

Stalker, L. A., L. A. Ciminski, D. C. Adams, T. J. Klopfenstein, and R. T. Clark. 2007. Effects of weaning date and prepartum protein supplementation on cow performance and calf growth. Rangeland Ecol. Manage. 60:578-587.

Stegeman, J. H. J. 1974. Placental development in the sheep and its relation to fetal development. Bijdr. Dierkd. 44:3-72.

Swanson, T. J., C. J. Hammer, J. S. Luther, D. B. Carlson, J. B. Taylor, D. A. Redmer, T. L. Neville, J. J. Reed, L. P. Reynolds, J. S. Caton, and K. A. Vonnahme. 2008. Effects of plane of nutrition and selenium supplementation on colostrum quality and mammary development in pregnant ewe lambs. J. Anim. Sci. 86:2415-2423.

Underwood, K. R., J. F. Tong, J. M. Kimzey, P. L. Price, E. E. Grings, B. W. Hess, W. J. Means, and M. Du. 2008. Gestational nutrition affects growth and adipose tissue deposition in steers. Proc. Western Sec. Am. Soc. Anim. Sci. 59:29-32.

Vogel, G. J., and C. Parrott. 1994. Mortality survey in feedyards: The incidence of death from digestive, respiratory, and other causes in feedyards on the Great Plains. Comp. Cont. Ed. Prac. Vet. 16:227-234

Vonnahme, K. A., S. P. Ford, M. J. Nijland, and L. P. Reynolds. 2004a. Alteration in cotyledonary (COT) vascular responsiveness to angiotensin II (ANG II) in beef cows undernourished during early pregnancy. Biol. Reprod. 70(Suppl. 1):110. (Abstr.)

Vonnahme, K. A., L. P. Reynolds, M. J. Nijland, and S. P. Ford. 2004b. Impacts of undernutrition during early to mid gestation on basal vascular tone of the cotyledonary and caruncular arterial beds in the bovine placentome. J. Soc. Gynecol. Investig. 11(Suppl.):222A. (Abstr.)

Vonnahme, K. A., M. J. Zhu, P. P. Borowicz, T. W. Geary, B. W. Hess, L. P. Reynolds, J. S. Caton, W. J. Means, and S. P. Ford. 2007. Effect of early gestational undernutrition on angiogenic factor expression and vascularity in the bovine placentome. J. Anim. Sci. 85:2464-2472.

Wallace, J. M., D. A. Bourke, and R. P. Aitken. 1999. Nutrition and fetal growth: Paradoxical effects in the overnourished adolescent sheep. J. Reprod. Fertil. Suppl. 54:385-399.
Wallace, L. R. 1948. The growth of lambs before and after birth in relation to the level of nutrition. J. Agric. Sci. (Camb.) 38:243-300, 367-398.

Ward, S. S., and N. C. Stickland. 1991. Why are slow and fast muscles differentially affected during prenatal undernutrition. Muscle Nerve 14:259-267.

Wohrley, J. D., M. G. Frid, E. P. Moiseeva, E. C. Orton, J. K. Belknap, and K. R. Stenmark. 1995. Hypoxia selectively induces proliferation in a specific subpopulation of smooth muscle cells in the bovine neonatal pulmonary arterial media. J. Clin. Invest. 96:273-281.

Wilson, S. J., J. J. Ross, and A. J. Harris. 1988. A critical period for formation of secondary myotubes defined by prenatal undernourishment in rats. Development 102:815-821.

Wittum, T. E., and L. J. Perino. 1995. Passive immune status at postpartum hour 24 and long-term health and performance of calves. Am. J. Vet. Res. 56:1149-1154.

Wittum, T. E., M. D. Salman, M. E. King, R. G. Mortimer, K. G. Odde, and D. L. Morris. 1994. Individual animal and maternal risk factors for morbidity and mortality of neonatal beef calves in Colorado, USA. Prev. Vet. Med. 19:1-13.

Wu, G., F. W. Bazer, J. M. Wallace, and T. E. Spencer. 2006. Board invited review. Intrauterine growth retardation: Implications for the animal sciences. J. Anim. Sci. 84:2316-2337.

Wu, G., and S. M. Morris Jr. 1998. Arginine metabolism: Nitric oxide and beyond. Biochem. J. 336:1-17.

Wu, G., W. G. Pond, S. P. Flynn, T. L. Ott, and F. W. Bazer. 1998. Maternal dietary protein deficiency decreases nitric oxide synthase and ornithine decarboxylase activities in placenta and endometrium of pigs during early gestation. J. Nutr. 128:2395-2402.

Wu, G., and J. T. Self. 2005. Proteins. Pages 757-759 in Encyclopedia of Animal Science. W. G. Pond and A. W. Bell, ed. Marcel Dekker Inc., New York, NY.

Zeng, X., S. E. Wert, R. Federici, K. G. Peters, and J. A. Whitsett. 1998. VEGF enhances pulmonary vascular genesis and disrupts lung morph metric in vivo. Dev. Dyn. 211:215-227.

Zhu, M. J., M. Du, B. W. Hess, W. J. Means, P. W. Nathanielsz, and S. P. Ford. 2007. Maternal nutrient restriction upregulates growth signaling pathway in the cotyledonary artery of cow placentomes. Placenta 28:361-368.

Zhu, M. J., S. P. Ford, W. J. Means, B. W. Hess, P. W. Nathanielsz, and M. Du. 2006. Maternal nutrient restriction affects properties of skeletal muscle in offspring. J. Physiol. 575:241-250. 